\title{
Analysis of Healthy Lifestyle Habits and Oral Health in a Patient Sample at the Dental Hospital of the University of Barcelona
}

\author{
Aina Torrejon-Moya ${ }^{1} \mathbb{D}$, Beatriz Gonzalez-Navarro ${ }^{2}$, Elisabet Roca-Millan ${ }^{1} \mathbb{D}$, Albert Estrugo-Devesa $^{2} \mathbb{D}$ \\ and José López-López ${ }^{2, * \mathbb{D}}$ \\ 1 Faculty of Medicine and Health Sciences (Dentistry), University of Barcelona, \\ 08907 L'Hospitalet de Llobregat, Spain; aina.torrejon@gmail.com (A.T.-M.); erocamil@gmail.com (E.R.-M.) \\ 2 Oral Health and Masticatory System Group (Bellvitge Biomedical Research Institute), IDIBELL, Department \\ of Odontostomatology, Faculty of Medicine and Health Sciences (Dentistry), University of Barcelona, \\ 08907 Barcelona, Spain; beatrizgonzaleznavarro@gmail.com (B.G.-N.); \\ albertestrugodevesa@gmail.com (A.E.-D.) \\ * Correspondence: 18575j11@gmail.com or jl.lopez@ub.edu; Tel.: +34-606-45-73-62
}

\section{check for}

updates

Citation: Torrejon-Moya, A.; Gonzalez-Navarro, B.; Roca-Millan,

E.; Estrugo-Devesa, A.; López-López,

J. Analysis of Healthy Lifestyle Habits and Oral Health in a Patient Sample at the Dental Hospital of the University of Barcelona. Int. J. Environ. Res. Public Health 2021, 18 , 7488. https://doi.org/10.3390/ ijerph18147488

Academic Editor: Takaaki Tomofuji

Received: 4 June 2021

Accepted: 10 July 2021

Published: 14 July 2021

Publisher's Note: MDPI stays neutral with regard to jurisdictional claims in published maps and institutional affiliations.

Copyright: (c) 2021 by the authors. Licensee MDPI, Basel, Switzerland. This article is an open access article distributed under the terms and conditions of the Creative Commons Attribution (CC BY) license (https:// creativecommons.org/licenses/by/ $4.0 /)$.

\begin{abstract}
The association between general health and oral health has been studied over recent years In order to evaluate the lifestyle and the presence of healthy habits, a descriptive observational study was conducted from December 2018 to April 2019 with 230 patients, aged from 18 to 65 years old, that attended the Dental Hospital of the University of Barcelona for the first time. A total of 230 participants were considered, $98(43 \%)$ were men and $132(57 \%)$ were women, with a mean age of 37 years old. Our hypothesis was that patients with healthy habits had a better oral status in comparison with patients with bad lifestyle habits. No statistically significant results were found regarding oral hygiene between gender, smokers and patients with systemic pathology. Regarding a healthy lifestyle (High adherence to dietary intake), no statistically significant results were found. No significant differences were found regarding physical activity between male and female patients. Our hypothesis wasn't confirmed; therefore, we cannot conclude that patients with healthy habits have better oral status in comparison with patients with bad lifestyle habits. Consequently, more prospective longitudinal studies should be carried out.
\end{abstract}

Keywords: oral health; lifestyle; healthy habits; weight; body mass index; periodontal disease; cardiovascular disease

\section{Introduction}

The American Heart Association presented seven health parameters to reduce the risk of cardiovascular diseases: no smoking, being physically active, normal blood pressure, blood glucose, cholesterol levels, normal weight and a healthy diet [1].

In addition, obesity and other systematic diseases such as diabetes mellitus, hypertension and cardiovascular disease, increase across populations along with the degree of their development [2]; however, low socioeconomic status has been associated with a higher risk of both cardiovascular diseases and diabetes [3].

Several studies [2-4] agree that diet plays an important role in systemic disease prevention and life expectancy, along with physical activity, which should be established as a goal in order to maintain a healthy body.

Cardiovascular disease can be measured by indicators such as body mass index (BMI), waist circumference and waist-hip ratio [5,6]. As BMI increases, so do comorbid conditions. Consequently, physical activity and physical fitness are modifiers of mortality and morbidity related to obesity [3], which is a multifactorial disease that can be modulated by eating habits [4] and physical activity [3]. 
An association between general health and oral health has been studied during the recent years [7], in the same way previous studies showed an association between obesity and oral health $[8,9]$.

The oral microbial composition is different between obese and nonobese patients, which could mean that there is a relation between oral bacteria and obesity, although glycemic control was not associated with oral bacteria [10].

This association occurs not only during adulthood, since obese children, for example, tend to have earlier teeth eruption [11].

Like obesity, clear differences in oral health have been shown in tobacco users. Among current smokers and never smokers, current smokers have poorer oral health and more oral problems than former smokers or never smokers [12].

The association between obesity and periodontitis is consistent, with an increased risk of periodontitis in overweight individuals. Although the pathophysiology remains unclear it is probably due to chronic inflammation and oxidative stress [13].

The prevalence and the severity of the periodontal disease are related to overweight and the treatment response occurs in all age groups [14].

The bidirectional association between periodontitis and diabetes is well known [15], because of oral dysbiosis and modified healing processes. Nevertheless, periodontitis is associated with microvascular and macrovascular complications [16]. Diabetic retinopathy, which is a major complication in diabetic patients, is higher in patients with type II diabetes and fewer teeth [17].

Heart disease has been associated with periodontal disease several times over the past years [18], with an increase of cardiovascular disease and strokes reported in patients with periodontitis [19].

Accordingly, this study was conducted to answer the following question: does lifestyle habits affect the oral health status of patients who attend the Dental Hospital of the University of Barcelona?

Subsequently, we set out to evaluate the lifestyle and presence of healthy habits of a group of patients who attended as their first visit to the Dental Hospital of the University of Barcelona.

We hypothesized that patients with healthy habits would have better oral status in comparison with patients with bad lifestyle habits.

Other specific objectives were established, such as determining the patient's eating habits, establishing Body Mass Index (BMI), determining the level of physical activity, determining the patient's oral hygiene status, as well as determining the number of caries, apical periodontitis and periodontal state of the patient through an orthopantomography.

\section{Materials and Methods}

\subsection{Study Design}

A descriptive observational study was conducted from December 2018 to April 2019 with 230 patients aged from 18 to 65 years old that attended the Dental Hospital of the University of Barcelona for the first time. Written informed consent was obtained from the participants.

\subsection{Research Ethics}

The study protocol conforms to the ethical guidelines of the 1975 Declaration of Helsinki, and the present analysis was approved by the Ethics Committee of the Faculty of Dentistry, University of Barcelona (Comité d'Ética de l'Hospital Odontològic ceic.hospitalodontologic@ub.edu) on 29 September 2017, with the protocol number 31/207.

\subsection{Study Participants}

The patients were invited to participate in this study. Additionally, individuals with missing information on any of the covariates included in the multivariable regression models were also excluded. 
The examinations included an anthropometric evaluation, physical activity, dietary questionnaire and oral examination.

\subsection{Anthropometric Evaluation}

A standardized questionnaire was completed and covered professional status, oral health habits, last dental visit, public or private visit, smoking and drinking habits, general pathology and medication intake.

Anthropometric evaluation included measurements of weight and height to calculate body mass index (BMI) and abdominal perimeter (Table 1).

Table 1. Body Mass Index (BMI) and weight classification status. Adapted from Yang $Q$ et al and Doll S et al. [1,2].

\begin{tabular}{|c|c|}
\hline Weight Status & BMI $\left(\mathrm{Kg} / \mathrm{m}^{2}\right)$ \\
\hline Underweight & $<18.5$ \\
\hline Normal range & $18.5-24.9$ \\
\hline Overweight & 25-29.9 \\
\hline Obese & $>30$ \\
\hline
\end{tabular}

\subsection{Physical Activity Questionnaire}

Patients were asked if they practiced physical activity, if they walked, and in the case of an affirmative responses how many hours they walked per week. The same questions were asked regarding aerobic physical activity. If they gave an affirmative response, how many hours per week of aerobic physical activity was reported.

\subsection{Dietary Questionnaire}

A modified healthy nutrition questionnaire was completed following two guidelines and modifying that used by the Spanish Arteriosclerosis Society [20,21] (Table 2).

Table 2. Questionnaire provided to the patients. Adapted from Katsouyanni $\mathrm{K}$ et al. and Estruch R et al. [20,21].

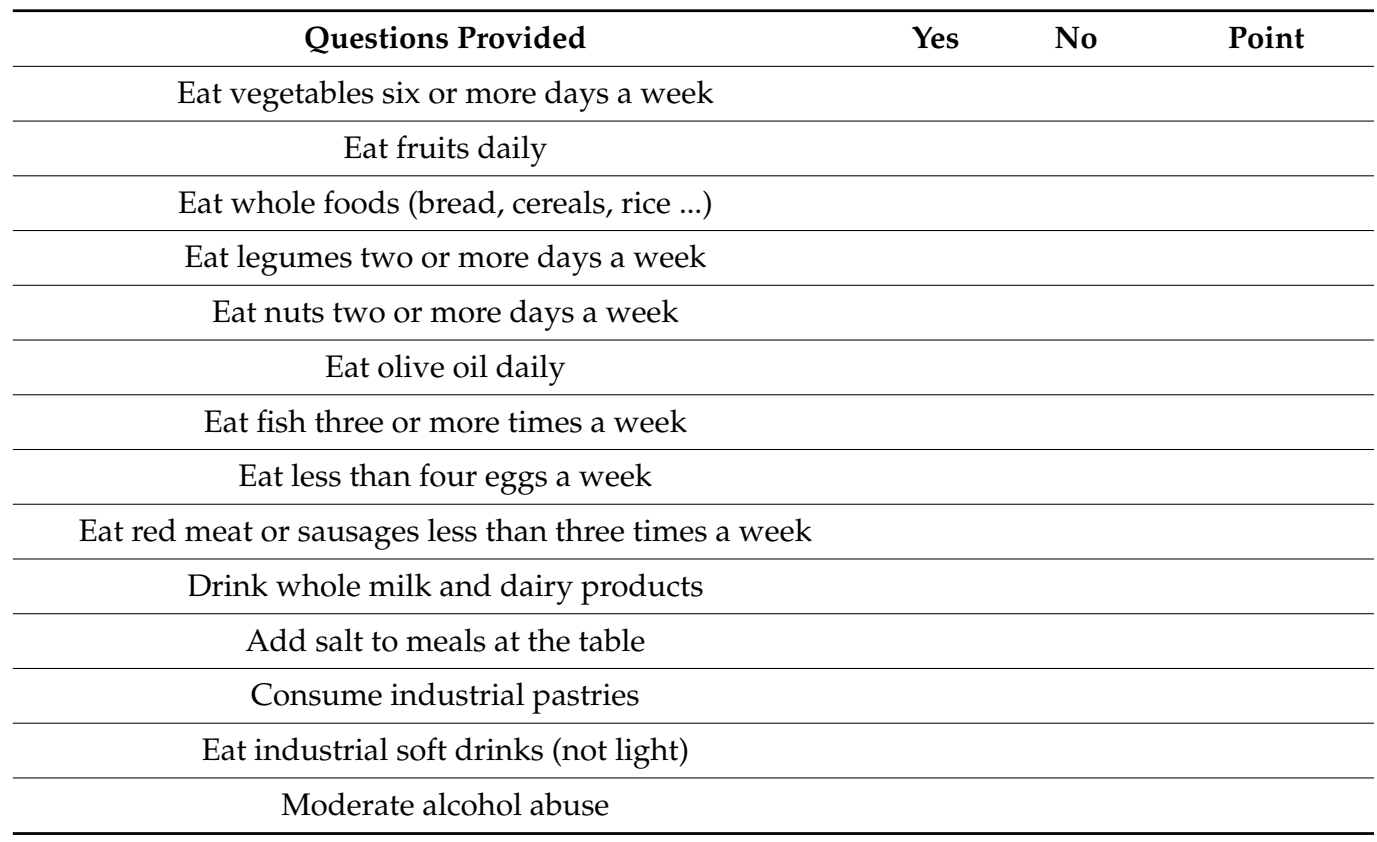

If the patient had nine or more points, the patient was considered as having high adherence, meaning dietary intake was good. 


\subsection{Dental Examination}

The dental examination was carried out by one trained dentist.

The total number of teeth were evaluated, as well as the presence of periapical lesions and their locations. The criteria were assessed by previously published criteria in the Orstravik periapical index (PAI) [22].

The endodontic burden [23], which consists of the sum of apical periodontitis, root canal treatment and the oral inflammatory burden [23] of each patient, was assessed. Oral inflammatory burden is divided into four categories and consists of the combination of evaluation of both the endodontic burden and periodontal disease.

The periodontitis severity index (PSI) [24] was assessed, taking into consideration that a PSI $<1$ is considered as no periodontal disease, between 1 and 1.9 is mild periodontal disease, between 2 and 2.9 is moderate periodontal disease and $>2.9$ is severe periodontal disease. Total dental index (TDI) [25] was estimated, which ranges from 0 to 10, the value increasing with severity. The orthopantomography index (OPGI) [25] was evaluated, which is the sum of chronic apical periodontitis, tertiary cavities, vertical deep pockets, radiolucent furcation area, and pericoronitis.

\subsection{Statistical Analyses}

Descriptive statistics were calculated for each of the studied features. A t-test was used for continuous variables, depending on distribution. For linear associations, the Pearson or Spearman correlation coefficient was used. An $\alpha=0.05$ level was considered statistically significant for all analyses.

\section{Results}

This section is divided by subheadings and provides a concise and precise description of the experimental results, their interpretation and the experimental conclusions that can be drawn.

\subsection{Study Population and Characteristics of the Study Participants}

A total of 230 participants were considered, 98 (43\%) were men and 132 (57\%) were women, with a mean age of 37.1 years old. The evaluated parameters are summarized in Table 3.

Table 3. Summarized biometric parameters. BMI = Body Mass Index. Data presented as mean (SD) or $N(\%)$.

\begin{tabular}{|c|c|c|c|c|c|}
\hline Biometric Parameters & Overall $(n=230)(\%)$ & $\begin{array}{l}\text { Healthy Lifestyle } \\
\text { (High Adherence) } \\
\quad(n=25)(\%)\end{array}$ & $p$-Value & $\begin{array}{l}\text { Self-Reported } \\
\text { Physical Activity } \\
(N=158)(\%)\end{array}$ & $p$-Value \\
\hline Age & $37.1(15.51)$ & $41.96(16.36)$ & 0.005 & $37.88(16)$ & 0.276 \\
\hline Gender (\%) & & & 0.077 & & 0.274 \\
\hline Male & $98(43)$ & $8(32)$ & & $71(44.9)$ & \\
\hline Female & $132(57)$ & $17(68)$ & & $87(55.06)$ & \\
\hline BMI (\%) & $24.44(9.76)$ & $23.96(5.58)$ & 0.391 & $24.82(4.37)$ & 0.140 \\
\hline Low BMI & $5(2.17)$ & $0(0)$ & & $2(1.26)$ & \\
\hline Normal & $124(53.48)$ & $18(72)$ & & $89(56.32)$ & \\
\hline High BMI & $101(43.91)$ & $7(28)$ & & $67(42.4)$ & \\
\hline Abdominal Perimeter & $90.96(24.56)$ & $88.16(12.19)$ & 0.198 & $90.89(25.32)$ & 0.929 \\
\hline Current Smokers (\%) & $54(23.48)$ & $3(12)$ & 0.054 & $39(24.68)$ & 0.837 \\
\hline Hypercholesteremia & $21(9.13)$ & $5(20)$ & 0.172 & $11(6.96)$ & 0.094 \\
\hline Statin medication & $9(3.91)$ & $1(4)$ & 0.623 & $6(3.79)$ & 0.901 \\
\hline
\end{tabular}


The mean BMI was 24.44. There were 124 (53.48\%) patients with a normal BMI and $101(43.91 \%)$ patients high a higher BMI.

\subsubsection{Systemic Pathology}

Regarding systematic pathology, 10 (4.35\%) patients reported being diabetic, 21 (9.13\%) patients reported hypercholesterolemia, and $18(7.83 \%)$ reported being hypertense. Patient medication was investigated. Four $(1.77 \%)$ patients used antiaggregant medication, 9nine (3.91\%) patients used hypocholesterolemia medication, nine (3.91\%) used anxiolytic medication, $15(6.52 \%)$ used a contraceptive pill, 21 (9.13\%) used antihypertensive medication and $10(4.35 \%)$ used antidepressant medication.

\subsubsection{Tobacco and Alcohol}

Concerning the tobacco habit, $54(23.48 \%)$ of the patients were current smokers, $29(12.61 \%)$ were ex-smokers and $147(63.91 \%)$ had never smoked. The mean number of cigarettes smoked per day was 10.4. Blond tobacco was more frequent (78-93.97\%) and filters were used by most consumers (71-85.54\%). The average number of years patients had been smoking was 9.78 .

With regard to alcohol consumption, $16(7.02 \%)$ patients were daily consumers, with a mean of 1.6 units of alcohol per day.

\subsubsection{Physical Activity}

In relation to physical activity, $158(68.70 \%)$ patients declared physical activity during their week. One hundred and seventy $(74.24 \%)$ stated weekly walking with the mean of walking hours at $7.7 \mathrm{~h}$ per week, and $96(41.74 \%)$ engaged in weekly aerobic activity such as soccer, tennis and gym activities, among others, with a mean of $4.31 \mathrm{~h}$ per week.

\subsubsection{Diet}

A total of 230 questionnaires were evaluated, and 25 (10.87\%) were classified as high adherence, meaning the participants had nine or more points in the questionnaire. Therefore, $205(89.13 \%)$ participants had low adherence regarding the dietary intake questionnaire.

\subsubsection{Oral Examination}

Regarding the oral evaluation, the results reported a mean of 26.04 teeth, $52(22.71 \%)$. For periapical lesions, the PAI of each periapical lesion was calculated, and the mean was 3.0, following the Orstavik Index [22]. Mean PSI was 0.89, meaning no periodontal disease, and the TDI mean was 1.89. The OPGI mean was 1.77.

The mean of the endodontic burden was 0.8 and for OIB was 1.4.

\subsubsection{Correlation between Variables}

No statistically significant results $(p>0.05)$ were found regarding oral hygiene, between gender, smokers and patients with systemic pathology. Regarding a healthy lifestyle (high adherence in dietary intake), no statistically significant results were found. No significant differences were found regarding physical activity between male and female patients.

Patients who had a healthier lifestyle reported less OPGI and TDI indexes (Table 4), although the results were not statistically significant. There were no statistically differences between apical lesions, PSI and cavities.

Patients who reported physical activity had less apical lesions (20.25-27.77\%) and reported higher OPGI and TDI indexes (Table 5), although the differences weren't statistically significant. No statistically differences were found regarding PSI and tertiary cavities. 
Table 4. Oral data and healthy lifestyle.

\begin{tabular}{cccc}
\hline Parameter Evaluated & $\begin{array}{c}\text { Healthy Lifestyle } \\
\text { (High Adherence) } \\
(\boldsymbol{n}=\mathbf{2 5}) \mathbf{( \% )}\end{array}$ & $\begin{array}{c}\text { Unhealthy Lifestyle } \\
(\text { Low Adherence) } \\
(\boldsymbol{n}=\mathbf{2 0 5})(\boldsymbol{\%})\end{array}$ & $p$-Value \\
\hline OPGI & 1.48 & 1.8 & 0.248 \\
\hline TDI & 1.68 & 1.9 & 0.756 \\
\hline PSI & 1 & 0.88 & 0.394 \\
\hline Apical lesions & $6(24)$ & $46(22.43)$ & 0.826 \\
\hline Tertiary cavities & 0.44 & 0.46 & 0.329 \\
\hline
\end{tabular}

OPGI = Orthopantomography index. TDI = Total Dental Index. PSI = Periodontal Severity Index. Data presented as mean $(\mathrm{SD})$ or $N(\%)$.

Table 5. Oral data and weekly activity.

\begin{tabular}{cccc}
\hline Parameter Evaluated & $\begin{array}{c}\text { Weekly } \\
\text { Physical Activity } \\
(\boldsymbol{n}=\mathbf{1 5 8}) \mathbf{( \% )}\end{array}$ & $\begin{array}{c}\text { Lack of Physical } \\
\text { Activity } \\
(\boldsymbol{n}=\mathbf{7 2}) \mathbf{( \% )}\end{array}$ & $p$-Value \\
\hline OPGI & 1.92 & 1.44 & 0.167 \\
\hline TDI & 1.96 & 1.73 & 0.309 \\
\hline PSI & 0.86 & 0.96 & 0.480 \\
\hline Apical lesions & $32(20.25)$ & $20(27.77)$ & 0.262 \\
\hline Tertiary cavities & 0.43 & 0.5 & 0.763
\end{tabular}

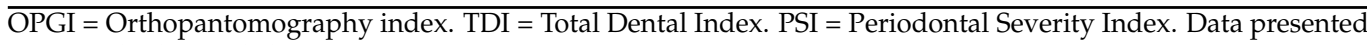
as mean (SD) or $N(\%)$.

\section{Discussion}

Answering our general objective; we cannot confirm that patients with wore lifestyle habits have worse oral health. In this study we analyzed several indicators of lifestyle habits such as, diet, physical activity, oral hygiene, smoking, obesity and cardiovascular parameters.

Regarding oral health, and in agreement with other studies [26], ours suggested that oral hygiene status was better in women than men, although the results weren't conclusive.

Smoking is a habit related to many health disorders, and although some studies indicate higher percentages of smokers in men than in women [26,27], our study did not find statistically significant differences between genders. Furthermore, the association between smoking and an increased risk of periodontitis concluded in some studies [8,28-30] could not be confirmed.

This is probably because the mean age of our sample (37.1) indicated a very young population, whereas Holde et al. [30] established that the mean age of a sample with periodontitis was 47.3 , and prevalence of periodontitis increased with age.

Holde et al. [30], also concluded that there was a $49.5 \%$ prevalence of periodontitis in a sample with a mean age of 47.3 , in comparison our study, which showed $39.56 \%$. Again, this difference can be explained by the mean age of our sample.

On the other hand, in our sample $23.48 \%$ of the patients were smokers, similar to the Spanish population (22.08\%) [31].

Regarding obese and overweight patients, many cross-sectional studies [8,27] have indicated an association between obesity and periodontal disease [27] and having a larger number of teeth has been shown to be associated with a lower risk of obesity [27-29]. In our study this relation couldn't be established, probably because the age of our sample was very young, and young patients tend to be more physically active [32]. On the other hand, and in agreement with our study, carious teeth showed no association with obesity $[8,27]$.

According to the ENSE [31] 17.4\% of adults are obese, and 37.1\% are overweight. Our study showed similar results, with $43.91 \%$ of the patients being overweight and obese. It 
was suggested that obesity was more frequent in men than women. Another parameter related to obesity is BMI.

Taking this into consideration, Östberg et al. [27] found that dental visits and regular dental habits had an association with waist circumference and BMI. This fact should be taken into consideration since according to the ENSE [31] only $50.32 \%$ of the Spanish population visited a dentist during the past year. From all the evaluated population $18.18 \%$ visited the dentist during the last three months or less, $6.95 \%$ confirmed they had never been to the dentist, and women visited the dentist more frequently than men [31]. On the other hand, Shimazaki et al. [33] established that subjects with severe periodontitis had higher BMI; this is in agreement with other articles [34-37] that stated that weight-gain was directly associated with development of periodontitis.

Oral health has been associated with cardiovascular diseases since 1989 [25]. Since that time there has been several studies associating periodontitis and cardiovascular diseases [38-40].

Taking into account that physical activity is very much related to cardiovascular diseases, $35.28 \%$ of the Spanish population have a low level of physical activity during the week [31]. Our study suggested higher percentages of $55.1 \%$ in female patients and $44.94 \%$ in male patients; therefore, our results agree with the statement that the percentage is higher in woman versus men. Several studies [9,40-42] concluded that low physical activity is associated with periodontal disease. In our study this association couldn't be confirmed because, as explained previously, the mean age in our study reflected a very young population, whereas periodontitis is associated with a much elderly population and increases with age [31]. Additionally, poor diet has been associated with periodontal disease [42]. We could not confirm this result for the same reason, i.e., periodontitis prevalence increases with age and our study involved a very young population.

The mean age of our study (37.1) indicated a very young population, providing probable bias in results. This made our results nonconclusive because younger people tend to have a healthier diet, do more physical activity, and their incidence of oral pathology is lower because it increases with age.

\section{Conclusions}

Our hypothesis wasn't confirmed. Therefore we cannot conclude that patients with healthy habits have a better oral status in comparison with patients with bad lifestyle habits.

Consequently, more prospective longitudinal studies should be carried out for an optimal evaluation.

Author Contributions: All authors made substantial contributions to conception and design of the study. A.T.-M. was involved in data collection and data analysis. A.T.-M., B.G.-N., E.R.-M., A.E.-D. and J.L.-L. were involved in data interpretation, drafting the manuscript and revising it critically and gave final approval of the version to be published. All authors have read and agreed to the published version of the manuscript.

Funding: This research received no external funding. This research did not receive any specific grant from funding agencies in the public, commercial, or not-for-profit sectors.

Institutional Review Board Statement: The study was conducted according to the guidelines of the Declaration of Helsinki, and approved by the Ethics Committee of the Faculty of Dentistry, University of Barcelona (Comité d'Ética de l'Hospital Odontològic ceic.hospitalodontologic@ub.edu) on 29 September 2017, with the protocol number 31/207.

Informed Consent Statement: Informed consent was obtained from all subjects involved in the study.

Conflicts of Interest: The authors declare no conflict of interest. 


\section{References}

1. Yang, Q.; Cogswell, M.E.; Flanders, W.D. Trends in cardiovascular health metrics and associations with all-cause, and CVD mortality among US adults. JAMA 2012, 307, 1273-1283. [CrossRef] [PubMed]

2. Doll, S.; Paccaud, F.; Bovet, P.; Burnier, M.; Wietlisbach, V. Body mass index, abdominal adiposity and blood pressure: Consistency of their association across developing and developed countries. Int. J. Obes. Relat. Metab. Disord. 2002, 26, 48-57. [CrossRef]

3. WHO/FAO Expert Consultation. Diet, Nutrition and the Prevention of Chronic Diseases; Report of the Joint WHO/FAO Expert Consultation, WHO Technical Report Series, No 916 (TRS 916); WHO/FAO Expert Consultation on Diet, Nutrition and the Prevention of Chronic Diseases: Geneva, Switzerland, 2003.

4. Peruchi, C.T.; Poli-Frederico, R.C.; Cardelli, A.A.; Fracasso, M.L.; Bispo, C.G.; Neves-Souza, R.D.; Cardoso, J.R.; Maciel, S.M. Association between oral health status and central obesity among Brazilian independent-living elderly. Braz. Oral Res. 2016, 30, e116. [CrossRef]

5. Bawadi, H.A.; Khader, Y.S.; Haroun, T.F.; Al-Omari, M.; Tayyem, R.F. The association between periodontal disease, physical activity and healthy diet among adults in Jordan. J. Periodont. Res. 2011, 46, 74-81. [CrossRef] [PubMed]

6. Molarius, A.; Seidell, J.C.; Sans, S.; Tuomilehto, J.; Kuulasmaa, K. Waist and hip circumferences, and waist-hip ratio in 19 populations of the WHO MONICA Project. Int. J. Obes. Relat. Metab. Disord. 1999, 23, 116-125. [CrossRef]

7. Jansson, L.; Kalkali, H.; Mulk Niazi, F. Mortality rate and oral health-A cohort study over 44 years in the county of Stockholm. Acta Odontol. Scand. 2018, 76, 299-304. [CrossRef] [PubMed]

8. Östberg, A.L.; Nyholm, M.; Gullberg, B.; Råstam, L.; Lindblad, U. Tooth loss and obesity in a defined Swedish population. Scand. J. Public Health 2009, 37, 427-433. [CrossRef]

9. Forslund, H.B.; Lindroos, A.K.; BLomkvist, K.; Hakeberg, M.; Berggren, U.; Jontell, M.; Torgerson, J.S. Number of teeth, body mass index, and dental anxiety in middle-aged Swedish women. Acta Odontol. Scand. 2002, 60, 346-352. [CrossRef] [PubMed]

10. Bloom, B.; Adams, P.F.; Cohen, R.A.; Simile, C. Smoking and oral health in dentate adults aged 18-64. NCHS Data Briefs 2012, $85,1-8$.

11. Šindelářová, R.; Soukup, P.; Broukal, Z. The relationship of obesity to the timing of permanent tooth emergence in Czech children. Acta Odontol. Scan. 2018, 76, 220-225. [CrossRef]

12. Tam, J.; Hoffmann, T.; Fischer, S.; Bornstein, S.; Gräßler, J.; Noack, B. Obesity alters composition and diversity of the oral microbiota in patients with type 2 diabetes mellitus independently of glycemic control. PLoS ONE 2018, 13, e0204724. [CrossRef]

13. Martinez-Herrera, M.; Silvestre-Rangil, J.; Silvestre, F.J. Association between obesity and periodontal disease. A systematic review of epidemiological studies and controlled clinical trials. Med. Oral Patol. Oral Cir. Bucal. 2017, 22, e708-e715. [CrossRef]

14. Suvan, J.E.; Finer, N.; D'Aiuto, F. Periodontal complications with obesity. Periodontol. 2000 2018, 78, 98-128. [CrossRef]

15. Mauri-Obradors, E.; Estrugo-Devesa, A.; Jané-Salas, E.; Viñas, M.; López-López, J. Oral manifestations of Diabetes Mellitus. A systematic review. Med. Oral Patol. Oral Cir. Bucal. 2017, 22, e586-e594. [CrossRef]

16. Pussinen, P.J.; Salomaa, V. Oral health: A neglected aspect of diabetes care. Lancet Diabetes Endocrinol. 2018, 6, 917-919. [CrossRef]

17. Song, S.J.; Han, K.; Lee, S.S.; Park, J.B. Association between the number of natural teeth and diabetic retinopathy among type 2 diabetes mellitus: The Korea national health and nutrition examination survey. Medicine 2017, 96, e8694. [CrossRef]

18. Li, C.; Lv, Z.; Shi, Z.; Zhu, Y.; Wu, Y.; Li, L.; Iheozor-Ejiofor, Z. Periodontal therapy for the management of cardiovascular disease in patients with chronic periodontitis. Cochrane Database Syst. Rev. 2017, 11, CD009197. [CrossRef] [PubMed]

19. Meurmann, J.; Sanz, M.; Janket, S.J. Oral health, atherosclerosis, and cardiovascular disease. Crit. Rev. Oral Biol. Med. 2004, 15, 403-413. [CrossRef] [PubMed]

20. Katsouyanni, K.; Rimm, E.B.; Gnardellis, C.; Trichopoulos, D.; Polychronopoulos, E.; Trichopoulou, A. Reproductibility and relative validity of an extensive semi-quantitative food frequency questionnaire using dietary records and biochemical markers among Greek Schoolteachers. Int. J. Epidemiol. 1997, 26 (Suppl. 1), S118-S127. [CrossRef] [PubMed]

21. Estruch, R.; Ros, E.; Salas-Salvadó, J.; Covas, M.I.; Corella, D.; Arós, F. Primary prevention of cardiovascular disease with a Mediterranean diet. N. Engl. J. Med. 2013, 368, 1279-1290. [CrossRef]

22. Orstavik, D.; Kerekes, K.; Eriksen, H.M. The periapical index: A scoring system for radiographic assessment of apical periodontitis. Endod. Dent. Traumatol. 1986, 2, 20-34. [CrossRef]

23. Gomes, M.S.; Hugo, F.N.; Hilgert, J.B.; Sant'Ana Filho, M.; Padilha, D.M.; Simonsick, E.M.; Ferrucci, L.; Reynolds, M.A. Apical periodontitis and incident cardiovascular events in the Baltimore Longitudinal Study of Ageing. Int. Endod. J. 2016, 49, 334-342. [CrossRef] [PubMed]

24. Holmlund, A.; Holm, G.; Lind, L. Severity of periodontal disease and number of remaining teeth are related to the prevalence of myocardial infarction and hypertension in a study based on 4254 subjects. J. Periodontol. 2006, 77, 1173-1178. [CrossRef] [PubMed]

25. Mattila, K.J.; Nieminen, M.S.; Valtonen, V.V.; Rasi, V.P.; Kesäniemi, Y.A.; Syrjälä, S.L.; Jungell, P.S.; Isoluoma, M.; Hietaniemi, K.; Jokinen, M.J. Association between dental health and acute myocardial infarction. BMJ 1989, 298, 779-781. [CrossRef]

26. Kitagawa, M.; Kurahashi, T.; Matsukubo, T. Relationship between General Health, Lifestyle, Oral Health, and Periodontal Disease in Adults: A Large Cross-sectional Study in Japan. Bull. Tokyo Dent. Coll. 2017, 58, 1-8. [CrossRef] [PubMed]

27. Östberg, A.L.; Bengtsson, C.; Lissner, L.; Hakeberg, M. Oral health and obesity indicators. BMC Oral Health 2012, 12, 50. [CrossRef] [PubMed]

28. AlJehani, Y.A. Risk factors of periodontal disease: Review of the literature. Int. J. Dent. 2014, 2014, 182513. [CrossRef] 
29. Reibel, J. Tobacco and oral diseases. Update on the evidence, with recommendations. Med. Princ. Pract. 2003, 12, 22-32. [CrossRef]

30. Holde, G.E.; Oscarson, N.; Trovik, T.A.; Tillberg, A.; Jönsson, B. Periodontitis Prevalence and Severity in Adults: A Cross-Sectional Study in Norwegian Circumpolar Communities. J. Periodontol. 2017, 88, 1012-1022. [CrossRef]

31. Ministerio de Sanidad, Consumo y Bienestar Social. ENSE Encuesta Nacional de Salud; Ministry of Health, Consumption and Social Welfare: Madrid, Spain, 2017.

32. Hallal, P.C.; Andersen, L.B.; Bull, F.C.; Guthold, R.; Haskell, W.; Ekelund, U. Global physical activity levels: Surveillance progress, pitfalls, and prospects. Lancet 2012, 380, 247-257. [CrossRef]

33. Shimazaki, Y.; Egami, Y.; Matsubara, T.; Koike, G.; Akifusa, S.; Jingu, S.; Yamashita, Y. Relationship between obesity and physical fitness and periodontitis. J. Periodontol. 2010, 81, 1124-1131. [CrossRef] [PubMed]

34. Gorman, A.; Kaye, E.K.; Apovian, C.; Fung, T.T.; Nunn, M.; Garcia, R.I. Overweight and obesity predict time to periodontal disease progression in men. J. Clin. Periodontol. 2012, 39, 107-114. [CrossRef]

35. Gorman, A.; Kaye, E.K.; Nunn, M.; Garcia, R.I. Changes in body weight and adiposity predict periodontitis progression in men. J. Dent. Res. 2012, 91, 921-926. [CrossRef] [PubMed]

36. Ekuni, D.; Mizutani, S.; Kojima, A. Relationship between increases in BMI and changes in periodontal status: A prospective cohort study. J. Clin. Periodontol. 2014, 41, 772-778. [CrossRef] [PubMed]

37. Stenman, U.; Wennström, A.; Ahlqwist, M.; Bengtsson, C.; Björkelund, C.; Lissner, L. Association between periodontal disease and ischemic heart disease among Swedish women. A cross-sectional study. Acta Odontol. Scand. 2009, 67, 193-199. [CrossRef] [PubMed]

38. Al-Zahrani, M.S.; Borawski, E.A.; Bissada, N.F. Increased physical activity reduces prevalence of periodontitis. J. Dent. 2005, 33, 703-710. [CrossRef]

39. Al-Zahrani, M.S.; Borawski, E.A.; Bissada, N.F. Periodontitis and three health-enhancing behaviors: Maintaining normal weight, engaging in recommended level of exercise, and consuming a high-quality diet. J. Periodontol. 2005, 76, 1362-1366. [CrossRef] [PubMed]

40. Samnieng, P.; Ueno, M.; Zaitsu, T.; Shinada, K.; Wright, F.A.; Kawaguchi, Y. The relationship between seven health practices and oral health status in community-dwelling elderly Thai. Gerodontology 2013, 30, 254-261. [CrossRef]

41. Wakai, K.; Kawamura, T.; Umemura, O. Associations of medical status and physical fitness with periodontal disease. J. Clin. Periodontol. 1999, 26, 664-672. [CrossRef]

42. Merchant, A.T.; Pitiphat, W.; Rimm, E.B.; Joshipura, K. Increased physical activity decreases periodontitis risk in men. Eur. J. Epidemiol. 2003, 18, 891-898. [CrossRef] 